\title{
A GRASP model in network design for two-stage supply chain
}

\author{
Hassan Javanshir $^{\mathrm{a}^{*}}$ and Mahdis Haghighi Ghashti ${ }^{\mathrm{a}}$
}

${ }^{a}$ Department of Industrial Engineering, Islamic Azad University, South Tehran Branch, Tehran, Iran

\begin{tabular}{l}
\hline A R T I C L E I N F O \\
\hline Article history: \\
Received 1 August 2010 \\
Received in revised form \\
10 November 2010 \\
Accepted 20 November 2010 \\
Available online \\
21 November 2010 \\
\hline Keywords: \\
Network design \\
Lead time \\
Safety stock \\
Inventory lost \\
GRASP \\
\hline
\end{tabular}

\section{A B S T R A C T}

We consider a capacitated facility location problem (CFLP) which contains a production facility and distribution centers (DCs) supplying retailers' demand. The primary purpose is to locate distribution centres in the network and the objective is the minimization of the sum of fixed facility location, pipeline inventory, safety stock and lost sales. We use Greedy randomized adaptive search procedures (GRASP) to solve the model. The preliminary results indicate that the proposed method of this paper could provide competitive results in reasonable amount time.

(C) 2011 Growing Science Ltd. All rights reserved.

\section{Introduction}

Supply chain management (SCM) is the management of material, information and financial flows through a network of organizations that aims to produce and deliver products or services for the consumers. The supply chain is faced with some risks such as inherent uncertainties and natural risks. There are different issues on managing the risk associated with supply chain such as supply management, demand, product and information management. Supply network design is one of the strategic plans of supply management (Tang, 2006). The distribution networks' design is one of the most important decisions in supply chain (SC) where the primary objective is to determine the appropriate distribution centers (DCs) to supply retailers' demand (Sourirajan et al., 2007). The safety stock in cases where customer's demands are stochastic is influenced by lead time (Eppen \& Martin, 1988; Karmarkar, 1993; Yang \& Geunes, 2007). Sourirajan et al. (2007) consider a single product network design model that contains fixed facility location, the pipeline inventory and safety stock costs. The objective is to locate distribution centers at certain sites to serve groups of retailers. Each DC has limited capacity and could hold saftey stock to satisfy retailers' demands. This is a single product network design model lead time and safety stock consideration (SPNDLS) which consists of lead time and safety stock. SPNDSL is a non-linear integer programming problem which is

* Corresponding author. Tel./fax: +98 2177508894

E-mail addresses: H_Javanshir@azad.ac.ir (H. Javanshir), 
recognized as NP-hard and Sourirajan et al. (2007) propose heuristic method to find near-optimal solutions using Lagrangian heuristic. Sourirajan et al. (2009) discuss the use of genetic algorithms (GA) for solving the SPNDLS problem.

In this paper, we present a network design model with lead time, safety stock and inventory lost. The objective is to locate distribution centers at some sites to minimize fixed facility location, the pipeline inventory, safety stock and lost sales expenditures. The costumers' demands must be equal or more than service level and the unmet demand is assumed to be lost at DCs. Furthermore, when the safety stock cost to satisfy service level increases, the cost associated with lost sales decreases. Consequently, we present a model to serve the retailers in which the total costs are minimum. We discuss the use of greedy randomized adaptive search procedures (GRASP) to solve the resulted model and compare the performance the proposed model with another existing model without considering lost sales cost. It is interesting to note that the total cost of the proposed model is computed to be less than the compared model where the lost sales cost is not considered. The implementation of GRASP finds a feasible solution in construction phase and during the local search phase it improves the first solution. The CPU time for GRASP for large-scale problems is considered to be reasonable.

This paper is organized as follows. we first present the literature review section 2. In section 3, we describe the proposed model and the problem formulation. In section 4 we explore GRASP and the algorithm to solve the model and the computational experiments and the results are presented in section 5. Finally in section 6 we explain the conclusion and some future directions.

\section{Literature Review}

The uncapacitated facility location problem (UFLP) and the capacitated facility location problem (CFLP) locate DCs to serve the demands while minimizing the sum of fixed location and transportation costs. Both UFLP and CFLP are classified as NP-hard problems. CFLP has the capacity constraints that limit the demand which can be served by each candidate location ( Sourirajan et al., 2007; Sourirajan et al., 2009). Geoffrion and Graves (1974) and Van Roy (1986) present models for the CFLP and propose Bender's decomposition approach and Lagrangian to solve the resulted problems. Mazzola and Neebe (1999) develop Lagrangian heuristics to solve CFLPs under different assumptions without considering lead times and service levels. Berman and Larson (1985), Crainic and Laporte (1997), Owen and Daskin (1998), Jamil et al. (1999) and Eskigun et al. (2005) study lead times in network design. Eskigun et al. (2005) consider an outbound supply chain network design with lead time consideration. The model involves location of distribution facilities and transporting finished vehicles from the assembly plants to dealers.

Wang et al. (2002), Daskin et al. (2002) present the facility location models with stochastic customer demand. Ramasesh et al. (1991), Sedarage et al. (1999) and Anupindi and Akella (1993) consider uncertain lead times in supply chain. Hayya et al. (2009) consider inventory model when both demand and lead time are stochastic. The objective of their model is to find optimal order quantities and reorder levels to minimize ordering, holding with the consideration of safety stock and shortage costs. Andersson and Marklund (2000) consider a two-level distribution system with one central warehouse and $N$ non-identical retailers. They present a model to minimize holding which also contains safety stock and backorder costs. In their model, lead time is considered to be stochastic but warehouse capacity is not incorporated into the problem statement.

Absi et al. (2009) address a multi-item capacitated lot-sizing problem with setup times, safety stock and demand shortages without considering lead time. Song (2009) considers an integrated ordering and production control in a supply chain where the objective is to minimize the holding costs and the backordering costs and the capacity of warehouse is assumed to be finite. Thus the service rate is uncontrollable and the proposed model does not consider safety stock. Ghezavati et al. (2009) present a new mathematical model for designing distribution networks in a supply chain system. The 
objective of the model is to minimize different cost components associated with the opening DCs, shipments, holding inventory and inventory lost subject to service level constraint. They also consider some constraint for the probability of occurring loss of inventory in each scenario for any opened DC and the capacity of the DC is not captured in their model.

Sourirajan et al. (2007), Liu and Zhang (2009) and Park et al. (2010) consider lead times and safety stocks in network design. They study the effects of resource allocation on lead times and safety stock risk pooling benefits. In these cases Lagrangian heuristics used to obtain near-optimal solutions in reasonable computational time. The proposed model by Sorirajan explore the use of GAs based on binary vector and random keys encoding to solve the SPNDLS and illustrate the advantages of GAs over the Lagrangian heuristic for such problems. In this paper, we present a network design model with lead time, safety stock and inventory lost consideration where the retailers' demand is stochastic and present a greedy randomized adaptive search procedures (GRASP). The problem description and formulation of the model is presented in the next section.

\section{Problem Statement}

We propose a distribution network design model with lead time, safety stock and inventory lost. The objective is to locate DCs to serve the retailers such that the sum of fixed location, inventory (pipeline and safety stock) and inventory lost costs are minimized. The costumers' demands must be equal or more than service level and the unsatisfied demand is assumed to be lost at DCs.

The assumptions used for the proposed model are follows:

- The retailers' demands are independent and follow a Poisson process (Ozsen, 2004; Daskin, 2002; Shen, 2003; Ozsen, 2008).

- The products are shipped from the production facility to a DC in full truckloads (Sourirajan, 2007)

- For such a replenishment process, the replenishment lead time at a DC like the one considered by Sourirajan et al. (2007) has three components:

1. Load make-up time: The amount of time spent in the waiting area of the production equipments before the products are sent to the DC.

2. Constant DC replenishment time (time/unit): The replenishment lead time between the production facility and the DC due to the physical locations of facilities.

3. Congestion time: The amount of time which is spent in the unloading zone.

The retailer' demand is stochastic and the lead time is invariable. Due to this assumption the safety stock at a DC given by, $\left(z_{\alpha} \sqrt{\left.L \sum_{k \in K} \sigma_{k}^{2}\right)}\right.$, where $P\left(z \leq z_{\alpha}\right)=\alpha$ and $\alpha$ is the service level that has to be achieved at the retailers. Therefore the retailers' demands follow Poisson process, the variance is equal to the mean. Consequently the amount of safety stock is $\left(z_{\alpha} \sqrt{\left.L \sum_{k \in K} D_{k}\right)}\right.$, (Sourirajan, 2007).

\subsection{Formulation}

In order to present the formulation of our model, we adopt the notation and definition used by Sourirajan et al. (2007) and Ghezavati et al. (2009): 
Sets:

$k \quad$ set of retailers $(k=1, \ldots, N)$

$j \quad$ set of possible DC locations $(j=1, \ldots, N)$, the same as the set of possible retailer locations

Parameters:

$f_{j} \quad$ fixed cost of locating a DC at location $\mathrm{j}$

$C_{j} \quad$ capacity of the DC at location $\mathrm{j}$

$\theta_{j} \quad$ unit cost of pipeline inventory for the DC at location $\mathrm{j}$

$H_{j} \quad$ unit cost of safety stock at a DC at location j

$p_{j} \quad$ load make-up time parameter of lead time for a DC at location $\mathrm{j}$

$q_{j} \quad$ constant lead time component per unit for a DC at location j

$r_{j} \quad$ congestion parameter of lead time for a DC at location $\mathrm{j}$

$u_{j} \quad$ unit cost of lost

$D_{k} \quad$ mean demand at retailer $\mathrm{k}$

$\beta_{j} \quad$ adjusted holding cost per unit for a DC at location $\mathrm{j}$

$\alpha \quad$ service level that has to be achieved at the retailers

$z_{\alpha} \quad$ inverse of the Standard Normal for a probability of $\alpha$

Decision variables:

$Y_{j}=1 \quad$ if a DC is built at location $\mathrm{j}, 0$ otherwise

$X_{j k}=1$ if retailer $\mathrm{k}$ is assigned to DC at location $\mathrm{j}, 0$ otherwise

$\mathrm{S}_{\mathrm{j}} \quad$ probability of occurring inventory lost in DC at site $\mathrm{j}$

We consider the replenishment lead time $\left(L_{j}\right)$ at a DC at location $j$ as it is given by Sourirajan et al. (2007) which is as follows,

$L_{j}=\frac{p_{j}}{W_{j}}+q_{j}+\frac{r_{j}}{C_{j}-W_{j}}$

where 
$W_{j}= \begin{cases}\sum_{k} D_{k} X_{j k} & \text { if } \sum_{k} D_{k} X_{j k} \leq C_{j}\end{cases}$

and $\mathrm{W}_{\mathrm{j}}$ denotes the total amount of product assigned to the DC at location $j$. The pipeline inventory between the production facility and DC at location $j$ is then given by

$P I_{j}=L_{j} W_{j}$

The pipeline cost can be obtained as follows,

$\operatorname{Cost}_{L j}=\theta_{j} P I_{j}$.

The expected safety stock inventory and its cost at a DC at location $\mathrm{j}$ can be expressed as follows,

$S S_{j}=z_{\alpha} \sqrt{L_{j} \sum_{k} D_{k} X_{j k}}$

$\operatorname{Cost}_{S S j}=H_{j} S S_{j}$.

Let $\beta_{j}=H_{j} z_{\alpha}$, then the inventory lost cost at a DC at location $j$ can be stated as follows,

$\operatorname{Cost}_{I L j}=\left(B_{j}+S_{j} \sum_{k} D_{j} X_{j k}\right) u_{j}$,

where

$B_{j}=\sum_{k} D_{j} X_{j k}-W_{j}$,

$S_{j}=1-\sum_{v=0}^{C_{j}} \frac{e^{-\sum_{k} D_{j} X_{j k}} *\left(\sum_{k} D_{j} X_{j k}\right)^{v}}{v !}$

where $B_{j}$ and $S_{j}$ denote the the amount of lost and the probability of occurring loss of inventory in opened DC at location $j$. Therefore, the proposed problem model is formulated as follows,

$$
\begin{aligned}
& \operatorname{Min} \sum_{j} f_{j} Y_{j}+\sum_{j} \theta_{j}\left(p_{j}+q_{j} W_{j}+\frac{r_{j} W_{j}}{C_{j}-W_{j}}\right)+\sum_{j} \beta_{j} \sqrt{\left(\frac{p_{j}}{W_{j}}+q_{j} W_{j}+\frac{r_{j}}{C_{j}-W_{j}}\right) * \sum_{k} D_{k} X_{j k}} \\
& \quad+\sum_{j} u_{j}\left(\sum_{k} D_{j} X_{j k}-W_{j}+S_{j} \sum_{k} D_{j} X_{j k}\right)
\end{aligned}
$$

subject to

$X_{j k} \leq Y_{j} \quad \forall j, k$,

$\sum_{j} X_{j k}=1 \quad \forall k$, 
$S_{j}=1-\sum_{v=0}^{C_{j}} \frac{e^{-\sum_{k} D_{j} X_{j k} *\left(\sum_{k} D_{j} X_{j k}\right)^{v}}}{v !} \quad \forall j$,

$W_{j}=\left\{\begin{array}{l}\sum_{k} D_{k} X_{j k} \\ C_{j}\end{array}\right.$

if $\sum_{k} D_{k} X_{j k} \leq C_{j}$

Otherwise

$X_{j k}:\{0,1\} \quad \forall j, k$,

$Y_{j}:\{0,1\} \quad \forall j$.

The objective function (10) has four terms: the fixed facility location costs, the pipeline inventory costs between the production facility and the DCs, the safety stock costs at the DCs, the total and the expected costs of inventory lost in any opened DC. Constraint set (11) specifies that we can assign a retailer to a DC location whenever we locate a DC at j. Constraint set (12) states that each retailers can be assigned to exactly one DC. Constraint set (13) presents the probability of occurring loss of inventory in each opened DC. This occurrence happens when the retailers' demands at opened DC are more than DC's capacity. Let $X_{j}$ be the retailers' demands at DC $j$. Therefore the probability of occurring loss of inventory in this opened DC is equal to $X_{j} \geq C_{j}$. constraint (13) specifies the retailers' demands which follows a Poisson process. Constraint set (14) states the total amount of product assigned to the DC at location $j$ and finally constraint set (15) and (16) are the binary constraints.

\section{The GRASP Implementation}

Hart and Shogan (1987) proposed a multi-start approach based on greedy randomized constructions called semi-greedy heuristic where no local search is used. GRASP was first introduced by Feo and Bard (1989a, 1989b). GRASP metaheuristic is a multi-start or iterative process, where each iteration consists of two phases: construction and local search (Feo \& Resende, 1989, 1995). The construction phase builds a feasible solution and local search phase investigates the neighborhoods to find local minimum. At each iteration of construction phase we select candidate elements and the candidate set $C$ is defined for each problem. The incremental costs, $c(e)$ for all $e \in C$ (the candidate elements) are evaluated (greedy evaluation function) and then the restricted candidate list (RCL) is built. For making RCL, let $\mathrm{c}^{\min }$ and $\mathrm{c}^{\max }$ be the smallest and the largest incremental costs, respectively. The threshold value for elements in RCL is $\left(\mathrm{c}^{\min }+\alpha\left(\mathrm{c}^{\mathrm{max}}-\mathrm{c}^{\mathrm{min}}\right)\right) \alpha \in[0,1]$. If the value of $c(e)$ is lower than or equal to the threshold value, the candidate element can be inserted to RCL. After making RCL, an element from the RCL is selected, randomly. Finally the candidate set $C$ is updated and the incremental costs $c(e)$ for all $e \in C$ are reevaluated. The local search replaces current solution with better solution which is in the neighborhood of current solution. For local search the neighborhood investigates in two ways: best-improving or first-improving strategy. In the bestimproving strategy we consider all neighbors for finding best solution. In the case of first-improving strategy we consider the neighbors till find the first solution where the cost function value is smaller than the current solution (Resende \& Ribeiro, 2002). In this paper we use the first-improving strategy since the computation times is smaller than the best-improving strategy.

\subsection{Steps of GRASP for the proposed model}

In this paper we present GRASP to find the near optimal solution for the proposed model. Sourirajan et al. (2007) developed the Lagrangian heuristic to find near optimal solution for the SPNDLS which is similar to our model. In this case they explain the necessary steps to find lower and upper bound for the proposed problem. The structure of GRASP to solve the problem in some steps, is similar to Lagrangian heuristic. It uses both greedy heuristic and randomize algorithm in making construction 
phase. Then it searches the neighbors to find first-improved solution. At each iteration the necessary steps of the algorithm are as follows,

Construction phase:

Step 1: Index the list retailers as $k=1, \ldots, N$. Set $k=1$

Step 2: For $k$ th retailer compare the mean demand of retailer and capacity of DC location $j$, then compute the total amount of product assigned to the DC at location $j, W_{j}$, which is constraint set (14) and compute the probability of occurring loss of inventory in DC at location $j$ (9)

Step 3: For $k$ th retailer which is assigned to a DC at location $j$, compute the greedy evaluation function $c(e)$ which is the objective function of the proposed model (11)

Step 4: Let $\mathrm{c}^{\min }$ and $\mathrm{c}^{\max }$ be the smallest and the largest incremental costs, respectively, If the value of $c(e)$ is lower than or equal to $\left(c^{\min }+\alpha\left(c^{\max }-c^{\min }\right)\right)$ then insert the DC location $j$ to RCL

Step 5: Select a DC location $j$ randomly and set $X_{j k}=1$ and $Y_{j}=1$

Step 6: Let $k=k+1$, If $k>N$ then STOP and compute objective function value $f(11)$, Else go to step 1

Local search phase

Step 7: While the first solution with the objective function value of $f^{\prime}$ is less $f$ repeat step 1 to 6 .

\section{Computational Results}

The problem data for GRASP in this model is the same as that one used for testing Lagrangian heuristic and GA algorithm (Sourirajan, 2007; Sourirajan, 2009) for SPNDLS. The data was derived using the 1990 census in Daskin (1995). The problem sizes are 15-node, 49-node, 88-node and 150node which show the number of retailers. Each retailer locations are candidate for locating DCs. The capacity of DC is multiple of mean demand of retailer. We set the multiple equal to 1.25, 1.5, 1.75 and 2. The mean demand is equal to population for cities divided by $1,000,000$. In this case we use 97.75\% service level and $\mathrm{z}_{\alpha}=2$. The fixed cost for locating DCs is derived by Daskin (1995) and divided by $1,000,000$. The constant lead time component per unit for a DC at location $\mathrm{j}, \mathrm{q}_{\mathrm{j}}$, is equal to 10. The load make-up time $p_{j}$ and congestion parameter of lead time $r_{j}$ derived from the results of Eskigun' work (Eskigun, 2002). Let M denote the shipment size from plant to the DCs. We set M to the lowest mean demand among all retailers. Eskigun (2002) set $p=(M-1) / 2$ and $r=C$ where $C$ is the capacity of DCs. The problem data for unit cost of pipeline inventory $\theta_{j}$ and adjusted holding cost $\beta_{\mathrm{j}}$ were given in Ozsen (2004). The unit cost of lost $u_{j}$ is equal to 0.08. The iteration for GRASP in this experiment is set to 50 for 15-node and 49-node and 100 for 88-node and 150-node. We use the following notations in our comparison,

Gap: estimate the optimality gap for any problem instance given by ((objective value - the best objective value)/ the best objective value)*100. For the objective value we use average and worstcase results.

CPU: average CPU requirement per replication per instance (seconds)

In this paper, we code the GRASP with Visual Basic software and the results are present in the following section. 


\subsection{Computational results}

In this section, we present the average and the worst case gaps for different capacity multiple, CPU time and the average and the best solution results for 15-node, 49-node, 88-node and 150-node problem size where the results are obtained by running GRASP. Table 1 summarizes the the computational results.

\section{Table 1}

The Average and the worst-case gap for the various capacity multiple

\begin{tabular}{|c|c|c|c|c|c|c|c|c|}
\hline \multirow{2}{*}{$\begin{array}{l}\text { GRASP } \\
\text { gap }\end{array}$} & \multicolumn{2}{|c|}{ Cap Mult: 1.25} & \multicolumn{2}{|c|}{ Cap Mult: 1.5} & \multicolumn{2}{|c|}{ Cap Mult: 1.75} & \multicolumn{2}{|c|}{ Cap Mult: 2:00 } \\
\hline & Average & $\begin{array}{l}\text { Worst- } \\
\text { case }\end{array}$ & Average & $\begin{array}{l}\text { Worst- } \\
\text { case }\end{array}$ & Average & $\begin{array}{l}\text { Worst- } \\
\text { case }\end{array}$ & Average & $\begin{array}{l}\text { Worst- } \\
\text { case }\end{array}$ \\
\hline 15-Node & 0.139 & 0.242 & 0.000 & 0.000 & 0.011 & 0.053 & 0.030 & 0.040 \\
\hline 49-Node & 0.578 & 0.968 & 0.211 & 0.414 & 0.193 & 0.497 & 0.130 & 0.238 \\
\hline 88-Node & 0.080 & 0.401 & 0.253 & 0.484 & 0.780 & 1.662 & 0.133 & 0.302 \\
\hline 150- Node & 0.003 & 0.006 & 0.112 & 0.225 & 0.062 & 0.124 & 0.032 & 0.064 \\
\hline $\begin{array}{l}\text { Overall } \\
\text { (Avg/Max) }\end{array}$ & 0.200 & 0.968 & 0.144 & 0.484 & 0.261 & 1.662 & 0.081 & 0.302 \\
\hline
\end{tabular}

According to Table 1, as the proposed model is solved with GRASP for different problem sizes, the average and the worst case gaps are less than 1\% (except one result). The overall average and the worst case gap for different capacity are between $0.081 \%$ to $0.261 \%$ and $0.302 \%$ to $1.662 \%$, respectively. Table 2 presents the CPU time for various capacity and problem size. Table 2 shows that for one of the problem, as the capacity multiple changes, the CPU times do not change greatly. The reason could be because the algorithm at primary steps checks the capacity constraint and then it makes the greedy evaluation function $\mathrm{c}(\mathrm{e})$. Consequently the capacity multiples do not affect the CPU time in GRASP.

\section{Table 2}

CPU time for the various capacity multiple

\begin{tabular}{|c|c|c|c|c|c|c|c|c|}
\hline \multirow{2}{*}{$\begin{array}{l}\text { GRASP } \\
\text { CPU }\end{array}$} & \multicolumn{2}{|c|}{ Cap Mult: 1.25} & \multicolumn{2}{|c|}{ Cap Mult: 1.5} & \multicolumn{2}{|c|}{ Cap Mult: 1.75} & \multicolumn{2}{|c|}{ Cap Mult: 2:00 } \\
\hline & Average & $\begin{array}{l}\text { Worst- } \\
\text { case }\end{array}$ & Average & $\begin{array}{l}\text { Worst- } \\
\text { case }\end{array}$ & Average & $\begin{array}{l}\text { Worst- } \\
\text { case }\end{array}$ & Average & $\begin{array}{l}\text { Worst- } \\
\text { case }\end{array}$ \\
\hline 15-Node & 12 & 14 & 14 & 15 & 15 & 15 & 10 & 10 \\
\hline 49-Node & 64 & 64 & 64 & 65 & 66 & 66 & 70 & 71 \\
\hline 88-Node & 393 & 410 & 386 & 388 & 461 & 611 & 470 & 609 \\
\hline $\begin{array}{l}150- \\
\text { Node }\end{array}$ & 1167 & 1169 & 1129 & 1133 & 1120 & 1136 & 1148 & 1161 \\
\hline
\end{tabular}

Table 3 shows that if the capacity of the DCs increase, the cost of model would generally decrease.

\section{Table 3}

The average and the best solutions for the various capacity multiple solved with GRASP

\begin{tabular}{lllllllll}
\hline & \multicolumn{2}{c}{ Cap Mult: 1.25} & \multicolumn{2}{c}{ Cap Mult: 1.50} & \multicolumn{2}{c}{ Cap Mult: 1.75 } & \multicolumn{2}{c}{ Cap Mult: 2:00 } \\
\cline { 2 - 9 } & Average & $\begin{array}{l}\text { Best } \\
\text { Solution }\end{array}$ & Average & $\begin{array}{l}\text { Best } \\
\text { Solution }\end{array}$ & Average & $\begin{array}{l}\text { Best } \\
\text { Solution }\end{array}$ & Average & $\begin{array}{l}\text { Best } \\
\text { Solution }\end{array}$ \\
\hline 15-Node & 24.692 & 24.658 & 23.680 & 23.680 & 22.155 & 22.153 & 21.480 & 21.474 \\
49-Node & 40.922 & 40.687 & 39.278 & 39.195 & 38.038 & 37.965 & 35.984 & 35.937 \\
88-Node & 29.489 & 29.466 & 30.529 & 30.452 & 31.193 & 30.952 & 29.971 & 29.931 \\
150- Node & 68.645 & 68.643 & 68.763 & 68.686 & 69.269 & 69.226 & 66.103 & 66.082 \\
\hline
\end{tabular}




\section{Conclusion}

In this paper, we have proposed a network design model with the consideration of lead time, safety stock and inventory lost. In this model, we consider lead time for supplying the retailers, service level and unmet demands. We have solved the resulted model with GRASP and the performance of the proposed model was examined using some numerical test problems and the results are also analyzed. The results show that the average and the worst case gaps are less than $1 \%$ and the CPU times are almost the same for different capacities.

As a the future, we could consider the stochastic lead time as an additional design parameter for the proposed model. CFLP model can be also extended using stochastic lead time and demand by considering safety stock and inventory lost.

\section{Acknowledgment}

The authors would like to thank the anonymous referees for their valuable comment on earlier version of this work.

\section{References}

Absi, N., \& Sidhoum, S.K. (2009). The multi-item capacitated lot-sizing problem with safety stocks and demand shortage costs. Computers \& Operations Research. 36, 2926-293.

Andersson, J., \& Marklund, J. (2000). Decentralized inventory control in a two-level distribution system. European Journal of Operational Research. 127, 483-506.

Anupindi, R., \& Akella, R. (1993). Diversification under supply uncertainty. Management Science. 39 (8), 944-963.

Berman, O. \& Larson, R.C. (1985). Optimal 2-facility network districting in the presence of queuing. Transportation Science. 19(3), 261-277.

Crainic, T. G. \& Laporte, G. (1997). Planning models for freight transportation. European Journal of Operational Research. 97, 409-438.

Daskin, M. S. (1995). Network and discrete location models, algorithms and applications. Interscience Series in Discrete Mathematics and Optimization. Wiley, New York.

Daskin, M. S., Shen, Z.-J.M., \& Coullard, C. (2002). An inventory-location model: Formulation, solution algorithm and computational results. Annals of Operations Research, 110, 83-106.

Eppen, G. D., \& Martin, R. K. (1988). Determining safety stock in the presence of stochastic lead time and demand. Management Science. 34 (11), 1380-1390.

Eskigun, E. (2002). Outbound supply chain network design for a large-scale automotive company. Unpublished Doctoral Dissertation, School of Industrial Engineering, Purdue University, West Lafayette, IN, USA.

Eskigun, E., Uzsoy, R., Preckel, P. V., Beaujon, G., Krishnan, S. \& Tew, J. D. (2005). Outbound supply chain network design with mode selection, lead times and capacitated vehicle distribution centers. European Journal of Operational Research. 165, 182-206.

Feo, T. A., \& Bard, J. F. (1989a). Flight scheduling and maintenance base planning. Management Science. 35,1415-1432.

Feo, T. A., \& Bard, J. F. (1989b). The cutting path and tool selection problem in computer-aided process planning. Journal of Manufacturing Systems. 8,17-26.

Feo, T. A., \& Resende, M. G. C. (1989). A probabilistic heuristic for a computationally difficult set covering problem. Operations Research Letters. 8, 67-71.

Feo, T. A., \& Resende, M. G. C. (1995). Greedy randomized adaptive search procedures. Journal of Global Optimization. 6, 109-133.

Geoffrion, A. M. \& Graves, G.W. (1974). Multicommodity distribution system design by Benders Decomposition. Management Science, 30 (5), 822-845. 
Ghezavati, V. R., Jabal-Ameli, M. S., \& Makui, M. (2009). A new heuristic method for distribution networks considering service level constraint and coverage radius. Expert Systems with Applications, 36, 5620-5629.

Hart, J. P., \& Shogan, A. W. (1987). Semi-greedy heuristics: An empirical study. Operations Research Letters, 6, 107-114.

Hayya, J. C., Harrison, T. P., \& Chatfield, D. C. (2009). A solution for the intractable inventory model when both demand and lead time are stochastic. International Journal of Production Economics, 122, 595-605.

Jamil, M., Baveja, A. \& Batta, R. (1999). The stochastic queue center problem. Computers \& Operations Research, 26, 1423-1436.

Karmarkar, U. (1993). Manufacturing lead times, order release and capacity loading. In: Graves, S.C., Rinnooy Kan, A.H.G., Zipkin, P. (Eds.), Handbooks in Operations Research and Management Science, 4. Elsevier, Amsterdam, 288-291.

Liu, X.F. \& Zhang, M. (2009). Cost optimization model of distribution systems in supply chain under stochastic demand. Chinese Control and Decision Conference.

Mazzola, J. B. \& Neebe, A. W. (1999). Lagrangean relaxation based solution procedures for a multiproduct capacitated facility location problem with choice of facility type. European Journal of Operational Research. 115, 285-299.

Owen, S. H. \& Daskin, M. S. (1998). Strategic facility location: a review. European Journal of Operational Research. 111, 423-447.

Ozsen, L. (2004). Location-inventory planning models: Capacity issues and solution algorithms. Unpublished Doctoral Dissertation, Northwestern University, Evanston, IL, USA.

Ozsen, L., Coullard, C. R., \& Daskin, M. S. (2008). Capacitated warehouse location model with risk pooling. Naval Research Logistics. 55 (4), 295-312.

Park, S., Lee, T. E., \& Sung, S. C. (2010). A three-level supply chain network design model with risk-pooling and lead times. Transportation Research Part E. 46, 563-581.

Ramasesh, R., Ord, J., Hayya, J., \& Pan, A.(1991). Sole versus dual sourcing in stochastic lead-time (s, Q) inventory models. Management Science. 37, 428-443.

Resende, M.G.C., \& Ribeiro, C.C. (2002). Greedy randomized adaptive search procedures. AT \& T Labs Research Technical Report TD-53RSJY, version 2.

Sedarage, D., Fujiwara, O., \& Luong, H. (1999). Determining optimal order splitting and reorder level for n-supplier inventory systems. European Journal of Operational Research. 116, 389-404.

Shen, Z-J. M., Coullard, C., \& Daskin, M. S. (2003). A joint location-inventory model. Transportation Science. 37, 40-55.

Song, D. P. (2009). Optimal integrated ordering and production policy in a supply chain with stochastic lead-time, processing-time, and demand. IEEE Transactions on Automatic Control. 54(9), 2027-2041.

Sourirajan, K., Ozsen, L., \& Uzsoy, R. (2007). A single product network design model with lead time and safety stock considerations. IIE Transactions. 39 (5), 411-424.

Sourirajan, K., Ozsen, L., \& Uzsoy, R. (2009). A genetic algorithm for a single product network design model with lead time and safety stock considerations. European Journal of Operational Research. 197, 599-608.

Tang, S. C. (2006). Perspectives in supply chain risk management: a review. International Journal of Production Economics. 103, 451-488.

Van Roy, T. J. (1986). A cross decomposition algorithm for capacitated facility location. Operations Research. 34, 145-163.

Wang, Q., Batta, R. \& Rump, C.M. (2002). Algorithms for a facility location problem with stochastic customer demand and immobile servers. Annals of Operations Research. 111, 17-34.

Yang, B., \& Geunes, J. (2007). Inventory and lead time planning with lead-time-sensitive demand. IIE Transactions. 39 (5), 439-452. 